\title{
Epidemiology of inflammatory bowel disease in sub-Saharan Africa: A review of the current status
}

\author{
G Watermeyer, ${ }^{1}$ FCP (SA); D Epstein, ${ }^{2}$ FCP (SA); O Adegoke, ${ }^{3}$ FMCPath; C Kassianides, ${ }^{4}$ FCP (SA); O Ojo, ${ }^{5}$ FMCPath; M Setshedi, ${ }^{1}$ PhD \\ ${ }^{1}$ Division of Gastroenterology, Department of Medicine, Faculty of Health Sciences, Groote Schuur Hospital and University of Cape Town, South Africa \\ ${ }^{2}$ Life Vincent Pallotti Hospital, Cape Town, South Africa \\ ${ }^{3}$ Department of Pathology, University College Hospital, University of Ibadan, Nigeria \\ ${ }^{4}$ Morningside Mediclinic, Johannesburg, South Africa \\ ${ }^{5}$ Gastroenterology and Liver Pathology Unit, Obafemi Awolowo University and Teaching Hospital, Ile-Ife, Nigeria
}

Corresponding author: G Watermeyer (gillian.watermeyer@uct.ac.za)

While inflammatory bowel disease (IBD) has been well characterised in the West and other parts of the world, there are little data from sub-Saharan Africa (SSA). To throw light on the current status of IBD in SSA, we performed a systematic review of the literature, extracting relevant publications. We found only 210 documented IBD cases in SSA (excluding South Africa (SA)), which were reported in 34 publications until August 2019. The majority were cases of ulcerative colitis. Only three reports, all from SA, attempted to determine IBD incidence rates. The rest were mostly case reports or small case series; the largest from Nigeria comprised 32 patients. The paucity of documented cases possibly reflects under-diagnosis and under-reporting. Major deficiencies in diagnostic and clinical capacity were noted, which need to be addressed going forward.

S Afr Med J 2020;110(10):1006-1009. https://doi.org/10.7196/SAMJ.2020.v110i10.14489

The term inflammatory bowel disease (IBD) mainly refers to two diseases, Crohn's disease (CD) and ulcerative colitis (UC). The aetiology of IBD remains unclear, but possibly reflects an aberrant interaction between T-cell immune responses, the microbiome and environmental triggers in genetically susceptible hosts. ${ }^{[1]}$ During the past 100 years, the incidence of IBD appears to have risen and subsequently plateaued in much of the western world. In a recent systematic review, $\mathrm{Ng}$ et al. ${ }^{[2]}$ provided a global perspective on the epidemiology of IBD in the 21st century. The authors also evaluated temporal trends and found that IBD was highest in the West, with prevalence rates of $>0.3 \%$ in North America, Oceania and many countries in Europe. However, $73 \%$ of studies on CD and $83 \%$ of studies on UC reported a stable or decreasing incidence of IBD in these regions.

In sharp contrast, there is a dearth of information on the epidemiology of IBD in SSA and its constituent countries. Since the advent of globalisation, there has been accelerated industrialisation in Asia, the Middle East and South America. The epidemiology of IBD appears to have mirrored this, with a rapid increase reported in areas where IBD has been considered uncommon in the past. ${ }^{[1,2]} \mathrm{Ng}$ et al. ${ }^{[2]}$ have shown that in newly industrialised nations across Asia, North Africa and South America, IBD incidence has increased over time.

Motivated by a need to fill the gap created by the limited information on IBD epidemiology in SSA, we performed a comprehensive review of the current literature on IBD in countries of the subregion. We also propose strategies to address the diagnostic and clinical deficiencies that the current dearth of information on IBD implies for the subregion.

\section{Methods}

An electronic search of the literature of the MEDLINE and Cochrane databases using medical subject headings ( $\mathrm{MeSH})$ terms and keywords, such as Crohn's disease, ulcerative colitis, inflammatory bowel disease, IBD, epidemiology, incidence, prevalence, sub-
Saharan Africa, Africa and individual country names, individually or in combination, were employed to identify SSA articles on IBD that were published until August 2019. We also collected journal articles from the references cited by the publications that we had obtained from the intitial search of the major databases listed above. The publications thus obtained, formed the main source of materials for this study.

\section{Results}

Only 3 studies, all from South Africa (SA), reported on IBD incidence rates. ${ }^{[3-5]}$ Over two time periods, 1970 - 1974 and 1975 - 1980, there was a significant increase in reported cases of IBD. Incidence rates for $\mathrm{CD}$ among the coloured, white and black population groups were $1.8,2.6$ and $0.3 / 100000$ per year, respectively, and for UC 1.9, 5.0 and $0.6 / 100000$ per year, respectively. ${ }^{[3-5]}$

Thirty-four additional publications were identified from all over the subregion, excluding SA. ${ }^{[6-40]}$ These were mostly case reports or small case series of patients diagnosed and managed in hospitals and clinics where the respective authors worked. Table 1 depicts details of these reports. A total of 210 cases of IBD were reported from SSA, excluding SA. ${ }^{[6-41]}$

Notably, of the aforementioned 34 publications, 1 was a single multicentre study. ${ }^{[41]}$ In that study, 118 missionaries working in 75 stations or hospitals associated with their missions, which were spread over 24 SSA countries, provided information about their medical practice over a 1-year period. Details were collected of the total number of patients seen during that year, and the number of cases of IBD encountered. Of $>1$ million outpatients and $\sim 190000$ inpatients who were seen by these doctors, only 22 cases of IBD were found. The authors did not specify the types of IBD seen in individual cases.

In 1998, Ogutu et al. ${ }^{[17]}$ from Kenya reported a cross-sectional study descibing abnormalities identified at colonoscopy over a 2 -year period. Consecutive patients $(n=247)$ underwent endoscopy 
Table 1. Analysis of published reports of inflammatory bowel disease in sub-Saharan African countries (excluding South Africa)

\begin{tabular}{|c|c|c|c|c|c|}
\hline Country & IBD, $n$ & UC, $n$ & $\mathrm{CD}, n$ & Not specified or IBD-U, $n$ & Author(s) and year \\
\hline \multirow[t]{2}{*}{ Burkino Faso } & 10 & 8 & 2 & - & Bougouma et al., 2002 \\
\hline & & & & & Ouedraogo et al., $2018^{[7]}$ \\
\hline Cameroon & 1 & 0 & 1 & - & Alegbeleye et al., 2019 $9^{[8]}$ \\
\hline \multirow[t]{3}{*}{ Ethiopia } & 13 & 5 & 8 & - & Kefenie et al., $1987^{[9]}$ \\
\hline & & & & & Mengesha et al., $1989^{[10]}$ \\
\hline & & & & & Mengesha et al., $1997^{[11]}$ \\
\hline \multirow[t]{2}{*}{ Ghana } & 45 & 24 & 4 & $17^{*}$ & Archampong and Nkrumah, $2013^{[12]}$ \\
\hline & & & & & Nkrumah, $2008^{[13]}$ \\
\hline \multirow[t]{2}{*}{ Ivory Coast } & 1 & 0 & 1 & - & Casanelli et al., 2004 $4^{[14]}$ \\
\hline & & & & & Okon et al.,2012 $2^{[15]}$ \\
\hline \multirow[t]{3}{*}{ Kenya } & 18 & 18 & 2 & - & Awori et al., 1972 \\
\hline & & & & & Ogutu et al., $1998^{[17]}$ \\
\hline & & & & & Steury and Templeton, $1980^{[18]}$ \\
\hline \multirow[t]{12}{*}{ Nigeria } & 63 & 35 & 22 & $6^{\dagger}$ & Greenwood and Larbi, $1966^{[19]}$ \\
\hline & & & & & Naish et al., 1970 ${ }^{[20]}$ \\
\hline & & & & & Khwaja et al., $1982^{[21]}$ \\
\hline & & & & & Alese and Irabor, $2008^{[22]}$ \\
\hline & & & & & Adi and Lloyd, 2010 $0^{[23]}$ \\
\hline & & & & & Ajayi et al., 2010 \\
\hline & & & & & Ukwenya et al., 2011 $1^{[25]}$ \\
\hline & & & & & Senbanjo et al., $2012^{[26]}$ \\
\hline & & & & & Alatise et al., $2012^{[27]}$ \\
\hline & & & & & Obaseki and Forae, $2014^{[28]}$ \\
\hline & & & & & Ekwunife et al., 2015 $5^{[29]}$ \\
\hline & & & & & Akere et al., 2016 ${ }^{[30]}$ \\
\hline \multirow[t]{2}{*}{ Rwanda } & 3 & 2 & 1 & - & Clerinx et al.,1995[31] \\
\hline & & & & & Kibaya, $1946^{[32]}$ \\
\hline \multirow[t]{4}{*}{ Senegal } & 14 & 14 & 0 & - & Aubry et al., 1984 ${ }^{[33]}$ \\
\hline & 1 & 0 & 1 & & Peghini et al., $1988^{[34]}$ \\
\hline & 2 & 0 & 2 & & Peghini et al., $1990^{[35]}$ \\
\hline & 2 & 2 & 0 & & Dia et al., $2014^{[36]}$ \\
\hline Tanzania & 1 & 1 & 0 & - & Jones et al., $1977^{[37]}$ \\
\hline Togo & 1 & 1 & 0 & - & Agoda-Koussema et al., 2012 $2^{[38]}$ \\
\hline Uganda & 4 & 4 & 0 & - & Billinghurst and Welchman, $1966^{[39]}$ \\
\hline Zimbabwe & 7 & 7 & 0 & - & Mguti, $1989^{[40]}$ \\
\hline SSA countries, $n=24$ & 22 & - & - & $22^{*}$ & Mayberry and Mann, $1989^{[41]}$ \\
\hline
\end{tabular}

during the study period. The major indications for colonoscopy were lower abdominal pain (35.6\%), non-bloody diarrhoea (22.3\%), constipation (21.4\%) and rectal bleeding (19.8\%). Fifty-three percent of patients had abnormal mucosal findings, the most common being proctocolitis $(20.2 \%)$. A histological diagnosis of nonspecific colitis was made in $28.5 \%$ and of UC in $7.3 \%$ of patients. There was 1 case of Crohn's colitis and 5 cases of infective colitis. ${ }^{[17]}$

One of the largest reports to date, from Ghana, identified 28 patients diagnosed with IBD between 2004 and 2011; 71\% were male, and in $21 \%$ symptoms lasted $>5$ years. ${ }^{[12]}$ Twenty-six patients had either UC or nonspecific colitis - only 2 had confirmed CD colitis. No cases of $\mathrm{CD}$ involving the small bowel were reported. Thirty percent of cases were diagnosed in patients aged between 20 and 30 years. Reported extra-gastrointestinal manifestations included finger clubbing, mouth ulcers, sacroiliitis and arthralgia, the last being the most prevalent. Treatment was limited to salazopyrine, antibiotics and corticosteroids. In 2008, the same centre reported 17 patients with IBD who were diagnosed between 1997 and 2001; again, the majority were cases of UC. ${ }^{[13]}$
In a series of 12 patients reported from Nigeria, the majority had UC. ${ }^{[27]}$ All patients presented with bloody diarrhoea. None of the patients had a family history of IBD, and no extra-intestinal manifestations were reported in association with the disease. As with the Ghanaian studies, treatment for UC and CD was nondiscriminatory and included 5-aminosalicylate preparations (almost all patients received salazopyrine), antibiotics and corticosteroids. None of the patients was treated with immunomodulators (azathioprine, 6-mercaptopurine or methotrexate) or biologics. ${ }^{[27]}$ The median delay of IBD treatment was 5 years, which was explained by the finding of entamoeba cysts in the stools of up to a third of patients at initial presentation. Therefore, they were first treated for amoebiasis with metronidazole, with no relief of symptoms. ${ }^{[27]} \mathrm{A}$ similar finding was reported in a Senagalese study of 14 patients with UC, where 4 had initially been treated for amoebiasis. ${ }^{[33]}$

In 2014, Obaseki and Forae ${ }^{[28]}$ from Nigeria reported 32 cases of IBD diagnosed over a 4-year period; 14 of CD, 12 of UC and 6 of IBD unclassified. Two-thirds of the patients were male. Thirty percent of the patients had isolated colonic CD and 53.9\% ileocolonic CD, 
while only 1 patient had isolated ileal involvement. In this report, azathioprine had been used as treatment, but none of the patients received biologics.

\section{Discussion}

During the past 100 years, the incidence of IBD appears to have risen and subsequently plateaued in much of the western world. ${ }^{[1,2]} \mathrm{A}$ similar trend has recently been noted in many newly industrialised nations across Asia, North Africa and South America. ${ }^{[2]}$

Recently, a preliminary analysis of a large IBD registry of $>3000$ SA patients showed an exponential increase in IBD over the past 70 years (David Epstein - personal communication, 2019). IBD now affects members of all ethnic groups, with UC appearing to be more prevalent in black patients, severe penetrating CD affecting an increased number of the Cape coloured community, and a relatively low prevalence of IBD among the Indian community (David Epstein personal communication, 2019).

With the exception of SA, IBD has long been considered uncommon in SSA. ${ }^{[41]}$ However, given the paucity of data describing the epidemiology of IBD in this subregion, the true burden of the disease remains largely unknown. Despite the 46 countries of SSA being home to more than a billion people, $<300$ cases were identified in this review, excluding SA. The first reported patient was from Rwanda (1946), and 4 cases of UC were described in Uganda in $1966 .{ }^{[32,39]}$ Subsequently, there have been other, albeit infrequent, case reports or small series from a number of countries in SSA, suggesting the rarity of IBD in the region. A 1989 study of rural mission hospitals in 24 SSA countries identified only 22 IBD cases among 1.19 million patients. ${ }^{[41]}$ Similarly, in Burkina Faso, of the 1221 colonoscopies performed from 1994 to 1997 , only 4 cases of IBD were detected. ${ }^{[6]}$

During recent years, however, the increasing number of published reports tends to suggest that the incidence of IBD in SSA may be increasing. ${ }^{[12]}$ A single report from Ghana showed a significant rise in the number of IBD patients seen at a single referral centre, with a $65 \%$ increase in case finding over 15 years. ${ }^{[12]}$ Additional reports have emerged from Nigeria, as well as other SSA countries, lending further credence to the notion of an apparent rise in incidence. ${ }^{[25]}$ A study from Kenya showed that, among patients referred for colonoscopy who had biopsies performed, 7\% had UC and 1 patient had CD. ${ }^{[17]}$ Heightened physician and patient awareness might have contributed to this apparent rise. A previous Ghanaian study showed that, while IBD was uncommon and diagnosis and commencement of treatment were often delayed, many patients were initially treated for infective colitis. ${ }^{[12]}$ This apparent rise in incidence may also reflect the increasing availability of diagnostic tools, such as flexible endoscopes, and the pathological expertise to appropriately interpret biopsies and bowel resection specimens. ${ }^{[25]}$

Given the current scenario of few case reports, lack of gastroenterology clinics and a dearth of IBD registries or populationbased surveys, it is impossible to estimate the prevalence of IBD in SSA. However, given the multiplicity of reports, it would be inaccurate to conclude that IBD is rare in this subregion. Quite possibly, diagnoses are often missed and hence it is quite conceivable that there is appreciable under-reporting of the disease. The dearth of published data on paediatric cases of IBD in SSA lends further credence to this suspicion. Although it is premature to draw firm conclusions, given the limited data, UC appears to be the more common type of IBD in SSA reports. The only exception to this pattern was provided by a recent study of 26 cases of IBD from Nigeria, where CD was diagnosed in the majority of cases. ${ }^{[28]}$ This is at odds with the data in other publications. One possible explanation is that intestinal tuberculosis (ITB) may have been misdiagnosed as CD. ITB may mimic CD and is important in the differential diagnosis, as the two conditions may be indistinguishable. In this series it is unclear whether ITB was actively excluded. ${ }^{[28,42]}$

Given that IBD may be uncommon in SSA, there will most likely be a continuing scarcity of population-based research or dedicated IBD registries. Therefore, without corrective measures, evaluating the epidemiology of IBD in SSA, understanding and exploring current trends will continue to be problematic for some time. Nonetheless, since 1950, SSA has continued to experience a rapid urbanisation, and if the incidence of IBD were to mirror that experienced in the West in similar sociodemographic circumstances as during the 20th century, the implications for IBD in SSA may be far reaching. ${ }^{[43,44]}$ SSA is home to several of the world's fastest growing economies, ${ }^{[45]}$ and if the expected burgeoning numbers of IBD patients in SSA were to be identified for treatment, diagnostic and clinical infrastructure will have to be improved to manage these complex, expensive-to-treat diseases. ${ }^{[46]}$

\section{Recommendations}

Evidently, there is a need to step up efforts to determine the true prevalence of IBD in SSA. A good starting point is to promote awareness of the disease through education of medical practitioners to improve their ability to readily recognise and diagnose it. In particular, there is a need to delineate IBD from other causes of chronic diarrhoea and infectious colitis. With correct diagnosis, issues of management can then be creditably addressed.

The future of IBD care in Africa also depends on efforts aimed at increasing diagnostic capacity across the region. This effort will require a multidisciplinary approach utilising the expertise of endoscopists, radiologists and pathologists, as endoscopic and histological confirmation are the standard of care in the diagnosis of IBD.

The paucity of pathology services in SSA remains a strong challenge that detracts from the diagnosis and prompt treatment of IBD patients in the region. For example, only 25 countries in SSA have formal pathology residency programmes ${ }^{[47]}$ and many hospitals function without the necessary pathology back-up services. In 2012, with the exception of Botswana and SA, all countries in SSA had $<1$ pathologist for every 500000 people, and many had $<1$ pathologist for every million people. ${ }^{[4]}$ Specialist gastroenterological pathologists are rarer still.

The IBD Working Group of the Gastroenterology and Hepatology Association of sub-Saharan Africa (GHASSA) was established in 2017 in an attempt to address these issues. The group aims, among other objectives, to increase the awareness of IBD in Africa, aid in the diagnosis and guide management to improve the quality of care of patients. The initial focus of the group is to educate healthcare professionals in SSA, including physicians, surgeons, radiologists, pathologists and endoscopists. The first task of the working group is to establish guidance on how to confirm the diagnosis of IBD, through education, as well as by improving endoscopic and histological skills.

\section{Conclusions}

The true burden of IBD in SSA remains unknown. Under-diagnosis, under-reporting, a lack of dedicated registries, inadequate facilities and a shortage of specialised health professionals all contribute to this epidemiological opacity.

To begin to address these deficiencies, appropriate education of medical practitioners needs to start in earnest.

Declaration. None.

Acknowledgements. None. 
Author contributions. GW and MS performed the literature search and the systematic review. All authors contributed to writing and editing of the manuscript.

Funding. None.

Conflicts of interest. None.

1. Kaplan GG, Ng SC. Understanding and preventing the global increase of inflammatory bowel disease. Kaplan GG, Ng SC. Understanding and preventing the global increase of inflammatort

Gastroenterology 2017;152(2):313-321. https://doi.org/10.1053/j.gastro.2016.10.020
Ng SC, Shi HY, Hamidi N, et al. Lancet 2017;390(10114):2769-2778. https://doi.org/10.1016/S01406736(17)32448-0

3. Wright JP, Marks IN, Jameson C, et al. Inflammatory bowel disease in Cape Town, 1975 - 1980. Part I. Ulcerative colitis. S Afr Med J 1983;63(7):223-226.

4. Wright JP, Marks IN, Jameson C, et al. Inflammatory bowel disease in Cape Town, 1975 - 1980. Part II. Crohn's disease. S Afr Med J 1983;63(7):226-229.

5. Wright JP, Froggatt J, O’Keefe EA, et al. The epidemiology of inflammatory bowel disease in Cape Town 1980 - 1984. S Afr Med J 1986;70(1):10-15.

6. Bougouma A, Drabo YJ, Serme AK, et al. Analysis of the results of 1221 colonoscopies in the hospitals of Burkina Faso. Bull Soc Pathol Exot 2002;95(1):50-52.

7. Ouedraogo S, Ouedraogo S, Kambire JL, et al. Epidemiological, clinical, histological and therapeutic features of primary digestive cancers in Burkina Faso. Bull Cancer 2018;105(12):1119-1125. https:// doi.org/10.1016/j.bulcan.2018.09.001

8. Alegbeleye B. Crohn's disease in a developing African mission hospital: A case report. J Med Case Rep 2019;13:80. https://doi.org/10.1186/s13256-019-1971-5

9. Kefenie H, NegesseY, Oljo G, Gebre-Selassie L. Crohn's disease in an Ethiopian. Ethiop Med J Kefenie H, NegesseY,
1987;225(4):181-184.

10. Mengesha B, Tsega E. Idiopathic ulcerative colitis among Ethiopian patients with chronic diarrhoea. Ethiop Med J 1989;27(2):63-72.

11. Mengesha B, Johnson O, Taye M, Gemetchu T. Crohn’s disease: Report of seven cases from Ethiopia. East Afr Med J 1997;74(6):397-399.

2. Archampong T, Nkrumah K. Inflammatory bowel disease in Accra: What new trends? West Afr J Med 2013;32(1):40-44.

13. Nkrumah K. Inflammatory bowel disease at the Korle Bu Teaching Hospital, Accra. Ghana Med 2008;42(1):38-41.

14. Casanelli JM, Keli E, N’Dri J, et al. Crohn’s disease: First report in Cote-d'Ivoire. Med Trop 2004;64:384-386. 15. Okon JB, Assi C, Diakité M, et al. [Pediatric colonoscopy at the University Hospital of Cocody (Ivory Coast)]. Med Sante Trop 2012;22(2):222-223. https://doi.org/10.1684/mst.2012.0038

16. Awori NW, Rees PH, Roy AD. Causes of chronic diarrhoea in Kenya and their relationship to ulcerative colitis. East Afr Med J 1972;49(8):604-613.

17. Ogutu E, Okoth F, Lule G. Colonoscopic findings in Kenyan African patients. East Afr Med J 1998; $75(9): 540-543$.

18. Steury E, Templeton A. Crohn's disease in Africa: A case report and review. Trop Geogr Med $1980 ; 32(2): 172-173$

19. Greenwood BM, Larbi EB. Ulcerative colitis in Africans. Br Med J 1966;1(5498):1300.

20. Naish J, Batchvarov B, Lawoyin V. A case of ulcerative colitis and pyostomatitis vegetans in an African Gut 1970;11:38-40. https://doi.org/10.1136/gut.11.1.38

21. Khwaja M, Thakur P, Lawrie J. Crohn's disease in a Nigerian. Arch Surg 1982;117(7):957-959. https:// doi.org/10.1001/archsurg.1982.01380310063015

22. Alese O, Irabor D. Pyoderma gangrenosum and ulcerative colitis in the tropics. Rev Soc Bras Med Trop 2008;41(6):664-667. https://doi.org/10.1590/s0037-86822008000600020

23. Adi A, Lloyd G. Crohn's disease: A case report. Nig Q J Hosp Med 2010;20(1):46-48.
24. Ajayi A, Chandrasekar T, Hammed A. Crohn's disease presenting as a recurrent perianal fistula: A case report. Niger J Clin Pract 2010;13(94):473-476.

25. Ukwenya A, Ahmed A, Odigie V, Mohammed A. Inflammatory bowel disease in Nigerians: Still a rare diagnosis? Ann Afr Med 2011;10(2):175-179. https://doi.org/10.4103/1596-3519.82067

26. Senbanjo IO, Oshikoya KA, Onyekwere CA, Abdulkareem FB, Njokanma OF. Ulcerative colitis in a Nigerian girl: A case report. BMC Res Notes 2012;5:564. https://doi.org/10.1186/1756-0500-5-564

27. Alatise OI, Otegbayo JA, Nwosu MN, et al. Characteristics of inflammatory bowel disease in three tertiary health centers in southern Nigeria. West Afr J Med 2012;31(91):28-33.

28. Obaseki DE, Forae GD. Clinicopathological features of inflammatory bowel disease in Benin City, Nigeria. Int J Adv Med Health Res 2014;1(1):16-19. https://doi.org/10.4103/2349-4220.134445

29. Ekwunife C, Nweke I, Achusi I, Ekwunife CU. Ulcerative colitis prone to delayed diagnosis in a Nigerian population: Case series. Ann Med Health Sci Res 2015;5(4):311-313. https://doi. org $/ 10.4103 / 2141-9248.160188$

30. Akere A, Oke T, Otegbayo J. Colonoscopy at a tertiary healthcare facility in Southwest Nigeria: Spectrum of indications and colonic abnormalities. Ann Afr Med 2016;15(3):109-113. https://doi. org/10.4103/1596-3519.188889

31. Clerinx J, Bogaerts J, Taelman H, et al. Chronic diarrhea among adults in Kigali, Rwanda: Association with bacterial enteropathogens, rectocolonic inflammation, and human immunodeficiency virus infection. Clin Infect Dis 1995;21(5):1282-1284. https://doi.org/10.1093/clinids/21.5.1282

2. Kibaya A. Possible case of Crohn's disease in a Ruanda native. East Afr Med J 1946; $23: 317-320$

33. Aubry P, Klotz F, Oddes B, Seurat PL. Hemorrhagic rectocolitis or ulcerative colitis in the black Senegalese. Apropos of 14 cases. Med Trop (Mars) 1984;44:269-278.

34. Peghini M, Barabe P, Veillard JM, et al. Gastric Crohn's disease (1st African case seen at the Hôpital Principal in Dakar). Dakar Med 1988;33(14):107-110.

35. Peghini M, Barabe P, Morcillo R, et al. Apropos of 2 recent cases collected at the Dakar Central Hospital. Dakar Med 1990;35(1):52-54.

36. Dia D, Cisse MC, Diouf G, et al. Severe acute colitis: Two fatal cases in Dakar. Med Sante Trop 2014;24(4):438-440

37. Jones ME, Bewes PC, Hulme-Moir I. Ulcerative colitis in an African: A fatal case in Tanzania. East Afr Med J 1977;54:670-673.

38. Agoda-Koussema LK, Anoukoum T, Djibril AM, et al. Ulcerative colitis: A case in Togo. Med Sante Trop 2012;22(1):79-81.

39. Billinghurst J, Welchman J. Idiopathic ulcerative colitis in the African: A report of 4 cases. Br Med J 1966;1(5481):211-213. https://doi.org/10.1136/bmj.1.5481.211

40. Muguti GI Ulcerative proctocolitis in black Zimbabweans. Cent Afr I Med 1989:35:300-303.

41. Mayberry J, Mann R. Inflammatory bowel disease in rural sub-Saharan Africa: Rarity of diagnosis in patients attending mission hospitals. Digestion 1989;44(3):172-176. https://doi.org/10.1159/000199907

42. Epstein D, Watermeyer G, Kirsch R. The diagnosis and management of Crohn's disease in populations with high-risk rates for tuberculosis. Aliment Pharmacol Ther 2007;25(12):1373-1388. https://doi.org /10.1111/j.1365-2036.2007.03332

43. United Nations Development Programme. Africa at a glance. http://www.africa.undp.org/content/rba/ en/home/regioninfo.htm (accessed 2 August 2019).

4. United Nations, Department of Economic and Social Affairs, Population Division. World urbanization prospects. 2018. https://esa.un.org/unpd/wup/Publications (accessed 2 August 2019).

45. International Monetary Fund. World Economic Outlook. 2019. https://www.imf.org/en/Publications/ WEO/Issues/2019/01/11/weo-update-january-2019 (accessed 2 August 2019).

46. Kamm MA. Rapid changes in epidemiology of inflammatory bowel disease. Lancet 2018;390(10114):2741-2742. https://doi.org/10.1016/S0140-6736(17)32669-7

47. Nelson AM, Hale M, Diomande MI, et al.Training the next generation of African pathologists. Clin Lab Med 2018;38(1):37-51. https://doi.org/10.1016/j.cll.2017.10.004

48. Adesina A, Chumba D, Nelson A. Improvement of pathology in sub-Saharan Africa. Lancet Oncol 2013;1494):e152-e157. https://doi.org/10.1016/S1470-2045(12)70598-3

Accepted 20 August 2020. 